
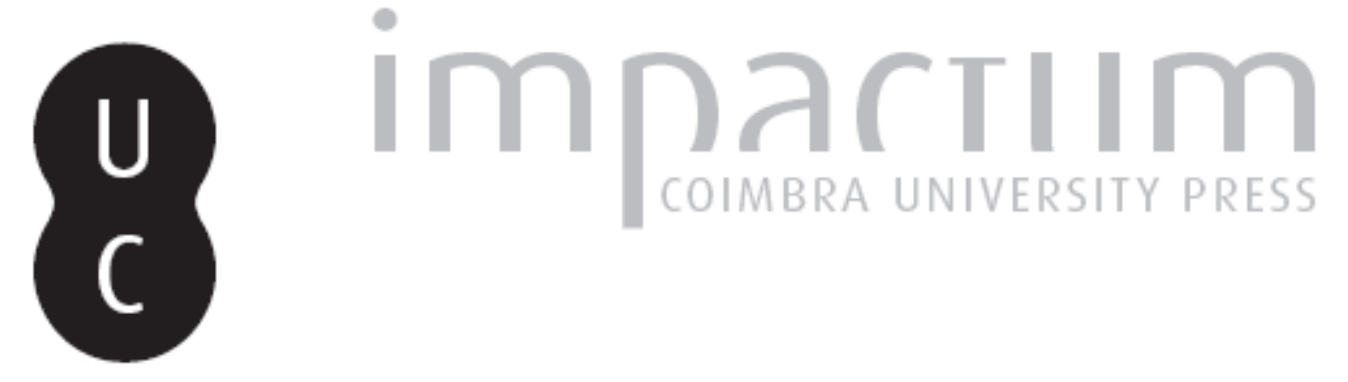

\title{
Higino, um mitógrafo latino em tradução: VI. O mito de Teseu e Ariadne
}
Autor(es):
Matias, Mariana Montalvão
Publicado por: Associação Portuguesa de Estudos Clássicos; Instituto de Estudos Clássicos

URL persistente:

URI:http://hdl.handle.net/10316.2/30432

DOI:

DOI:http://dx.doi.org/10.14195/0872-2110_50_4

Accessed : $\quad$ 26-Apr-2023 14:13:36

A navegação consulta e descarregamento dos títulos inseridos nas Bibliotecas Digitais UC Digitalis, UC Pombalina e UC Impactum, pressupõem a aceitação plena e sem reservas dos Termos e Condições de Uso destas Bibliotecas Digitais, disponíveis em https://digitalis.uc.pt/pt-pt/termos.

Conforme exposto nos referidos Termos e Condições de Uso, o descarregamento de títulos de acesso restrito requer uma licença válida de autorização devendo o utilizador aceder ao(s) documento(s) a partir de um endereço de IP da instituição detentora da supramencionada licença.

Ao utilizador é apenas permitido o descarregamento para uso pessoal, pelo que o emprego do(s) título(s) descarregado(s) para outro fim, designadamente comercial, carece de autorização do respetivo autor ou editor da obra.

Na medida em que todas as obras da UC Digitalis se encontram protegidas pelo Código do Direito de Autor e Direitos Conexos e demais legislação aplicável, toda a cópia, parcial ou total, deste documento, nos casos em que é legalmente admitida, deverá conter ou fazer-se acompanhar por este aviso.

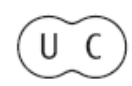




\section{Boletim de \\ Estudos Clássicos}

Associação Portuguesa de Estudos Clássicos Instituto de Estudos Clássicos

\section{Coimbra}

Dezembro de 2008 


\title{
Higino, UM MitógRafo LaTino EM TRAdUÇÃo VI. O Mito de TeSEU E ARIAdNe
}

\author{
que somente encontrando aquele fio, \\ o da voz de Ariana, poderei \\ reconduzir-me inteiro ao meu destino.
}

David Mourão-Ferreira

Numa organização da Livraria Minerva, do Instituto de Estudos Clássicos da Faculdade de Letras da Universidade de Coimbra e da Fluir Perene, as Terças-Feiras de Minerva da temporada 2007/08 encerraram com uma sessão de doutas palavras, mitos e poesia, subordinada ao tema "Labirinto e Minotauro". 1

O evento, que decorreu num quente final de tarde do mês de Julho, contou com a participação do Prof. Doutor José Ribeiro Ferreira que dissertou sobre o(s) mito(s) de Teseu, Ariadne e o Minotauro e apresentou o seu livro Labirinto e Minotauro: Mito de Ontem e de Hoje. Nesta obra, o autor traça um breve percurso pelos dados da tradição clássica relativos ao mito e analisa a sua influência e presença em seis poetas portugueses contemporâneos, a que se segue uma antologia dos principais poemas abordados. Coube ao Grupo de Poesia da Associação Cultural Thíasos, do Instituto de Estudos Clássicos da Faculdade de Letras da Universidade de Coimbra, a leitura de alguns dos textos poéticos seleccionados do volume sobre o mito do herói ateniense que, auxiliado pela apaixonada Ariadne, derrotou o terrível monstro que vivia encarcerado no labirinto arquitectado por Dédalo.

Assim, sob este mote, o grupo que se tem dedicado à tradução das Fabulae de Higino, dando continuidade à apresentação e exploração das estórias deste corpus, apresenta as fábulas 42 e 43 do mitógrafo latino. Estas versam, respectivamente, sobre a vitória de Teseu e do Minotauro e o "rapto"

1 Vide http://minervacoimbra.blogspot.com/2008/07/poesia-encerrou-terasfeiras-de-minerva.html (consultado em 20/11/2008). 
da filha de Minos, e sobre o abandono de Ariadne em Naxos, o enamoramento de Líber pela princesa e a morte de Egeu.

\section{THESEVS APVD MINOTAVRVM}

Theseus posteaquam Cretam uenit ab Ariadne Minois filia est adamatus adeo ut fratrem proderet et hospitem seruaret, ea enim Theseo monstrauit labyrinthi exitum, quo Theseus cum introisset et Minotaurum interfecisset, Ariadnes monitu licium reuoluendo foras est egressus, eamque, quod fidem ei dederat, in coniugio secum habiturus auexit.

\section{ARIADNE}

Theseus in insula Dia tempestate retentus, cogitans si Ariadnen in patriam portasset, sibi opprobrium futurum, itaque in insula Dia dormientem reliquit; quam Liber amans inde sibi in coniugium abduxit. 2. Theseus autem cum nauigaret oblitus est atra uela mutare, itaque Aegeus pater eius credens Theseum a Minotauro esse consumptum in mare se praecipitauit, ex quo Aegeum pelagus est dictum. 3. Ariadnes autem sororem Phaedram Theseus duxit in coniugium.

\section{TESEU E O MINOTAURO}

Depois de Teseu ter chegado a Creta, Ariadne, a filha de Minos, apaixonou-se por ele de tal forma que traiu o irmão e salvou o estrangeiro, uma vez que indicou a Teseu a saída do labirinto. Depois de entrar nele e matar o Minotauro, Teseu saiu cá para fora desenrolando um fio a conselho de Ariadne e, como the havia prometido, levou-a consigo para se casar com ela.

\section{ARIADNE}

Retido na ilha de Dia por uma tempestade, Teseu pensando que seria uma desonra para si se levasse Ariadne para a sua pátria, abandonou-a então na ilha de Dia, enquanto esta dormia. Logo Líber apaixonado por ela a tomou em casamento e a levou dali. 2. Teseu, porém, quando navegava, esqueceu-se de trocar as velas negras e assim o seu pai, julgando que Teseu fora devorado pelo Minotauro, lançou-se ao mar que, por causa disso, foi chamado mar Egeu. 3. Teseu, por seu lado, casou-se com Fedra, irmã de Ariadne. 


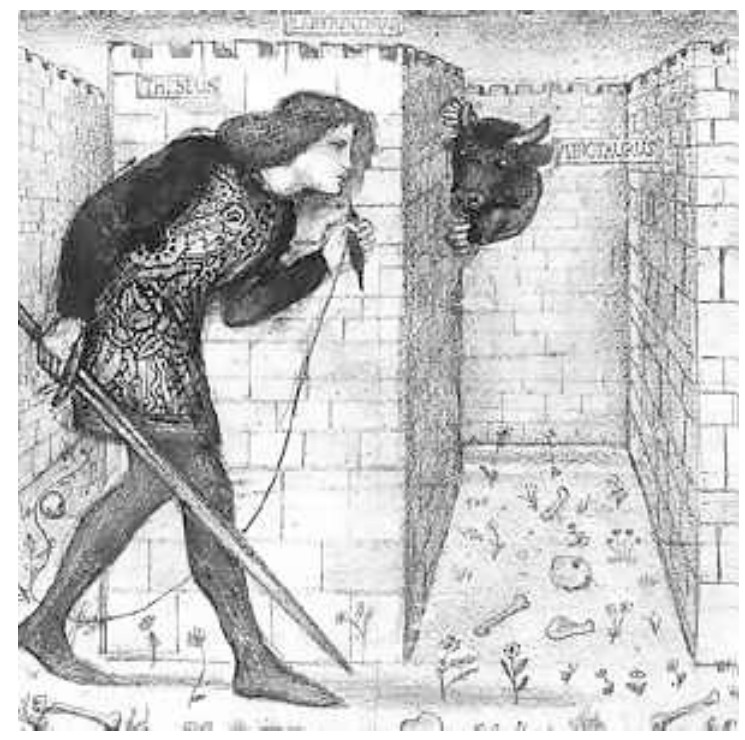

Sir Edward Burne-Jones, Theseus in the Labyrinth (1862)

\section{Higino e a tradição mitológica: o Minotauro e os (des)amores de Teseu e Ariadne}

Segundo a lenda, Minos, rei de Creta, filho de Zeus e de Europa, desde o início do seu reinado, atraiu a vingança e a cólera de Poséidon ao recusarlhe o sacrifício de um touro branco em sua honra. O deus, furioso com tal desobediência, fez suscitar na esposa do soberano, Pasífae, uma paixão avassaladora pelo animal. Desse amor irresistível e contranatural nasceu o Minotauro $^{2}$, uma criatura híbrida, com corpo de homem e cabeça de touro. Aterrado com este nascimento, Minos encarrega Dédalo, o engenhoso arquitecto, de construir um edifício especial onde fosse encarcerado o fruto monstruoso daquela união. Surge assim o Labirinto, uma estrutura composta por inúmeros corredores e salas enredadas que se cruzam sem cessar, de onde ninguém conseguiria sair, depois de lá entrar.

${ }^{2} \mathrm{O}$ nome pessoal do monstro seria Astério mas surge geralmente designado por Minotauro. 
Androgeu, filho de Minos e Pasífae, era um magnífico atleta cretense e a sua vitória nas Panateneias suscitou a inveja do rei de Atenas, Egeu, que o convidou a matar o touro de Creta. O jovem foi, porém, morto pelo animal ${ }^{3} \mathrm{e}$ o seu pai Minos resolveu vingar a morte do filho, empreendendo uma expedição contra a Grécia Continental, da qual saiu vencedor. A guerra terminou mas o rei cretense impôs um pesado tributo aos Atenienses: um grupo de sete jovens e sete raparigas deveria ser enviado regularmente ${ }^{4}$ para Creta a fim de servirem de alimento ao Minotauro.

Aquando do terceiro envio de jovens para o sacrifício, Teseu, filho de Egeu, ofereceu-se para embarcar com as vítimas para ir libertar a pátria deste imposto sangrento.

Reza ainda a lenda que, quando chegou a Creta, Ariadne, uma das filhas de Minos, se apaixonou por Teseu e o auxiliou na sua vitória sobre o Minotauro, fornecendo-lhe uma espada e um novelo de fio ${ }^{5}$ que permitiu ao ateniense não se perder nos sinuosos corredores do Labirinto. O filho de Egeu mata então o Minotauro e liberta Atenas da terrível sujeição. Parte rumo à terra-natal, levando consigo a apaixonada Ariadne que, entretanto, segundo a tradição mais corrente, abandona durante a viagem na ilha de Naxos $^{6}$, enquanto dormia. ${ }^{7}$ Aí encontra-a Dioniso e logo se apaixona por ela

3 Outras versões do mito contam que Androgeu foi morto, por instigação de Egeu, pelos concorrentes que o jovem vencera nos jogos de Atenas.

4 A periodicidade deste tributo varia conforme as versões da lenda: umas referem que o tributo seria anual, outras, de três em três anos, de sete em sete e ainda, de nove em nove anos.

5 Noutra versão, Teseu ter-se-ia guiado pela luz de uma coroa que Ariadne lhe dera, depois de ele lhe prometer que a levaria, se vencesse o Minotauro.

${ }^{6}$ Esta ilha primitivamente tinha o nome de Dia.

7 Nem todas as versões explicam a atitude de Teseu, mas algumas oferecem diferentes razões. Numa outra versão, foi o próprio Dioniso que pediu ao herói ateniense que deixasse Ariadne na ilha; outra variante refere que Teseu sentiu receio de que os atenienses o criticassem por este se casar com uma mulher que traíra a sua própria família e pátria; consta ainda uma versão em que Teseu abandona Ariadne porque amava Egle, filha de Panopleu; uma outra justificação é a de que Teseu terá conduzido a filha de Minos para a praia da ilha para amenizar o seu enjoo. Porém, um vento muito forte deixara o navio à deriva e quando ele consegue voltar encontra a princesa que, entretanto, morrera de parto. 
e a desposa ${ }^{8}$, oferecendo-lhe, como presente de casamento, uma coroa de ouro que colocou, em seguida, no número das constelações.

No regresso, o herói Teseu, na euforia de ter derrotado o monstro, esqueceu as recomendações do pai e não ergueu as velas brancas do navio, sinal de que saíra vitorioso da missão. Ao perscrutar a costa, Egeu avista, então, ao longe, as velas negras do barco e logo pensa que o filho perecera, morto pelo Minotauro. Desesperado, lança-se ao mar e morre.

Ainda que o mito do Labirinto seja um dos mais tratados ao longo dos tempos, quer no seu todo, quer na relação intrínseca que estabelece com alguns dos seus mitemas, designadamente Dédalo, Minotauro, Teseu, podemos afirmar que é escasso o relevo que os autores literários da época arcaica e clássica lhe atribuem. Existem, de facto, algumas alusões e referências breves que demonstram que a lenda de Teseu estava divulgada, mas nenhuma obra a apresenta como questão central. Na verdade, o mito, em todas as suas componentes - a ida do herói para Creta; o tributo ao Minotauro; a façanha de Teseu com a ajuda de Ariadne e o seu abandono em Naxos -, só aparece sistematizado e valorizado em autores gregos e romanos tardios.

Os Poemas Homéricos, primeiros documentos literários da literatura grega, em vários passos, ainda que breves, revelam o conhecimento do mito de Teseu e Ariadne.

Realçamos a referência ao salão de dança que Dédalo construíra para a Ariadne de belas tranças, na descrição do escudo de Aquiles (Il. 18. 592). Porém, mais significativo é o momento em que, na Odisseia, o herói Ulisses, na sua catábase ao mundo dos mortos, encontra as irmãs Fedra e Ariadne (Od. 11.321-5) e relata:

Vi Fedra e Prócris e a formosa Ariadne, filha de Minos de pensamentos funestos, que Teseu um dia trouxe de Creta para a cidadela da sagrada Atenas.

Não chegou porém a desfrutar dela. Antes, causou-lhe a morte [Ártemis

em Dia, rodeado pelo mar, por denúncia de Dioniso. ${ }^{9}$

8 Conta-se também que foi Afrodite, ao aperceber-se do desespero de Ariadne por ser abandonada, que teve pena desta e lhe prometeu um amante imortal, em lugar do ingrato mortal que a enganara.

9 Trad. de José Ribeiro Ferreira. 
Esta parece ser a primeira alusão ${ }^{10}$ na literatura grega ao confronto entre Teseu e o Minotauro, e o aspecto do mito privilegiado pelo ciclo épico é, pois, o abandono de Ariadne por Teseu, atribuído à intervenção de Dioniso que, em Naxos, a terá surpreendido nalgum sacrilégio e a denunciou a Ártemis que a matou. Esta versão foi, no entanto, suplantada, sendo a mais conhecida, como referimos anteriormente, a de que o herói ateniense teria abandonado a princesa em Naxos, enquanto esta dormia, quer pelo facto de amar outra mulher, quer por ter sido incitado pelo próprio Dioniso.

Quanto aos autores líricos, a poetisa Safo, Simónides e também Baquílides parecem ter tido conhecimento de alguns aspectos do mito de Teseu e do Minotauro. ${ }^{11}$

Também Eurípides, no séc. V, se debruça sobre esta temática na sua tragediografia, nomeadamente na intervenção de Teseu no Héracles (vv. 1326-1328) e possivelmente nas suas peças perdidas Cretenses e Teseu. ${ }^{12}$ Quanto a Ariadne, a sua estória não rendeu tragédias exclusivas, mas a temática da princesa que ajuda o forasteiro e posteriormente é vítima de traição encontramo-la, com matizes diferentes, na Medeia euripidiana.

As alusões e referências apontadas demonstram que, de facto, a lenda se encontrava divulgada. No entanto, esta só ganhou verdadeiro relevo em autores mais tardios como Diodoro Sículo, Estrabão e Plutarco (Vida de Teseu 15-23) e escritores romanos, designadamente Catulo e Ovídio. E serão, de facto, os poemas destes dois clássicos latinos as fontes mais utilizadas para aludir ao mito de Teseu e Ariadne.

No poema de Catulo, carme 64, conhecido como "As Bodas de Peleu e Tétis", o autor descreve a colcha da cama nupcial onde estava representado o abandono de Ariadne por parte do herói ateniense. Aí são narrados também o feito de Teseu, a imposição do tributo, a colaboração da filha de Minos, o seu abandono na ilha de Dia e a morte de Egeu, provocada pelo esquecimento da

10 Este passo tem sido, por vezes, considerado uma interpolação ática posterior. Vide U. Wilamowitz, Homerische Untersuchungen (Berlin 1884), p. 149; A. Heubeck e A. Hoekstra, A commentary on Homer's Odyssey (Oxford, 1989), ad. 11. 321-325.

11 Vide José Ribeiro Ferreira, Labirinto e Minotauro: Mito de Ontem e de Hoje (Coimbra, 2008), pp. 30-31; A. Barnabé, "El mito de Teseo en la poesia arcaica e clásica”, in R. Olmos (ed.), Coloquio sobre Teseo y la copa de Aison (Madrid, 1992), pp. 97-118.

12 Ferreira, op. cit., pp. 31-32. 
troca de velas. É de realçar a emotividade que perpassa por todo o poema, tendo Catulo enfatizado o sofrimento de uma princesa que se sacrificara, por amor, ao abandonar a própria família, para depois ser traída: Sicine me patriis avectam, perfide, ab aris,/ perfide, deserto liquisti in litore, Theseu? (vv. 132-3).

Ovídio aborda a temática em duas das suas obras. Em Heroídes 10. 1150, é Ariadne que fala na primeira pessoa e revela toda a sua dor e revolta por ter sido abandonada e traída por Teseu, mas também pelo sono e pelos ventos favoráveis que permitiram a partida do herói: In me iurarunt somnus uentusque fidesque (v. 117). Em Metamorfoses, no livro 8, Ovídio narra a expedição de Minos, o nascimento do Minotauro, a construção do Labirinto por Dédalo, a fuga deste e a mortal imprudência de Ícaro. Ầ infeliz história de amor entre Teseu e Ariadne dedica, em particular, os versos 172 a 182, referindo o abandono cruel de Ariadne por Teseu na ilha de Dia e o aparecimento de Líber ${ }^{13}$ que a salva e toma em casamento. Acrescenta ainda que, para a tornar eterna, o deus lançou nos céus a coroa nupcial de ouro que lhe oferecera, tornando-a numa constelação. ${ }^{14}$

Podemos assim verificar que Higino nas duas fábulas que dedica, em específico, a Teseu e Ariadne segue a versão de Catulo e a de Ovídio, a mais conhecida do mito.

$\mathrm{Na}$ fábula 42 relata o enamoramento de Ariadne pelo estrangeiro Teseu, o feito vitorioso do ateniense em Creta com a sua ajuda e o consequente rapto. Na seguinte, o mitógrafo latino narra que Teseu abandona Ariadne na ilha de Dia, enquanto esta dorme. Logo surge Líber que por ela se apaixona, a toma em casamento e a leva dali. A propósito do abandono cruel de Ariadne, Higino introduz uma nota justificativa que não consta da versão ovidiana: Teseu abandona a amada, pois temia ser criticado pelos atenienses por se casar com uma mulher que traíra os seus.

O castigo que o herói ateniense sofreu por não se ter lembrado de trocar as velas também não foi esquecido pelo mitógrafo. Higino refere assim que Egeu, ao avistar as velas negras do navio, julgou que o filho morrera e, por isso, se suicida, lançando-se ao mar, cuja designação teve origem no nome

13 Líber, deus do vinho sincretizado com Dioniso.

14 Séneca, na sua Fedra, apresenta uma pequena variação do mito, ao referir que a própria Ariadne se transformara em constelação, ao invés da coroa nupcial (vv. 663-664). 
dessa figura mitológica. O relato termina com uma breve referência ao posterior casamento de Teseu com Fedra, irmã de Ariadne.

Desde sempre o mito de Teseu, do Minotauro e de Ariadne exerceu um grande fascínio nos romancistas, poetas, músicos e pintores de todas as épocas. Na verdade, a figura mítica de Ariadne, as suas aventuras, desventuras e (des)amores mereceram a atenção de nomes como os de Lope de Vega em El Laberinto de Creta (1621), Calderón de la Barca com Los tres mayores prodigios (1636), Thomas Corneille, irmão de Pierre Corneille, com Ariane (1672), de Anton Tchékhov com o conto Ariane (1895), Richard Strauss e Hugo von Hofmannsthal na ópera Ariadne auf Naxos (1912), e Marguerite Yourcenar com Qui n'a pas son Minotaure? (1943), entre muitos outros.

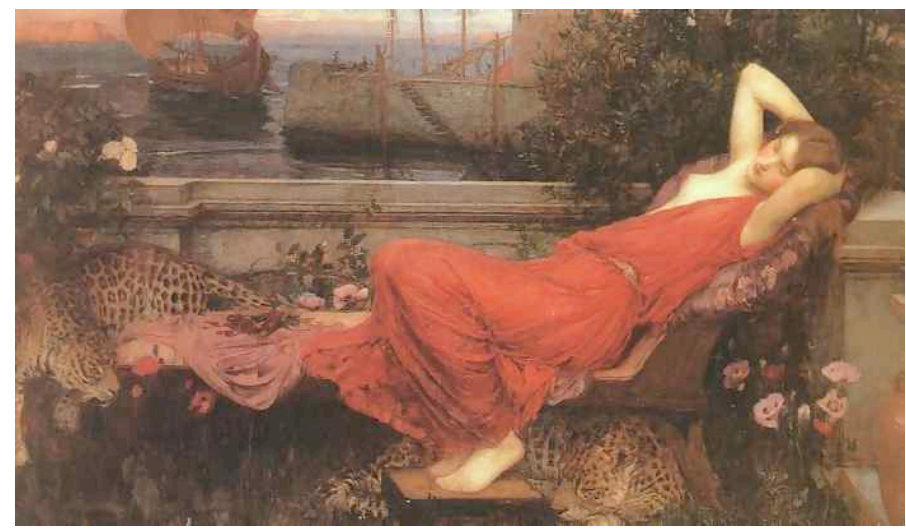

John William Waterhouse, Ariadne (1898)

\section{Tópicos de exploração didáctica}

Fábula 42

Sintaxe:

- complemento circunstancial de lugar 'para onde': formação com acusativo simples e supressão da preposição com nomes de cidades ou ilhas pequenas (Cretam);

- complemento circunstancial de companhia (secum); 
- voz passiva e complemento agente da passiva (ab Ariadne Minois filia est adamatus);

- oração subordinada consecutiva de adeo $u t+$ conjuntivo (adeo $u t$ fratrem proderet et hospitem seruaret);

- oração subordinada temporal-causal (cum introisset et Minotaurum interfecisset).

\section{Morfologia:}

- substantivos de flexão greco-latina (Theseus, Ariadne, Minois);

- pronome demonstrativo is, ea, id;

- pronome relativo qui, quae, quod;

- pretérito mais-que-perfeito do indicativo (dederat);

- pretérito imperfeito (proderet; seruaret) e mais-que-perfeito do modo conjuntivo (introisset; interfecisset);

- compostos de facio (interfecisset);

- verbos depoentes (est egressus);

- o gerúndio (reuoluendo).

\section{Fábula 43}

\section{Sintaxe:} Dia);

- complemento circunstancial de lugar 'onde': in + ablativo (in insula

- complemento agente da passiva em ablativo simples com seres inanimados (tempestate retentus);

- voz passiva e complemento agente da passiva (Theseum a Minotauro esse consumptum);

- oração subordinada completiva infinitiva (cogitans (...) sibi opprobrium futurum; credens Theseum a Minotauro esse consumptum);

- oração subordinada temporal-causal (Theseus autem cum nauigaret).

\section{Morfologia:}

- substantivos da flexão greco-latina (Theseus, Ariadne, Aegeus);

- pronome demonstrativo is, ea, id;

- pronome relativo qui, quae, quod;

- o pretérito perfeito do indicativo (reliquit; abduxit; praecipitauit); o pretérito imperfeito do conjuntivo (nauigaret); o pretérito mais-que-perfeito do conjuntivo (portasset); 
- o particípio presente: amans; cogitans; credens; dormientem;

- o infinitivo perfeito passivo (esse consumptum);

- verbo depoente obliuiscor e sua conjugação (oblitus est);

- o verbo duco e seu composto abduco (abduxit).

MARIANA MONTALVÃO HORTA E COSTA MATIAS 